\title{
Cytarabine Induced Reproductive Histopathological Changes in Albino Male Mice
}

$$
\text { تحفيز السيتار ابين للتغيرات النسيجية المرضية التكاثرية في ذكور الفئران البيض }
$$

$$
\begin{aligned}
& \text { Niran A. Ibrahim Hanady S. Al-Shmgani Ruqaya M. Ibrahim* } \\
& \text { College of Education for Pure Sciences (Ibn Al-Haitham)/ Baghdad University }
\end{aligned}
$$

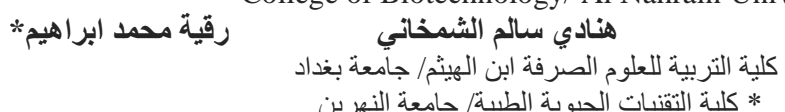

$$
\begin{aligned}
& \text { نيران علاء ابراهيم }
\end{aligned}
$$

E-mail: niran_alaa@yahoo.com

\begin{abstract}
Cytarabine (Ara-C) is widely used as an effective chemotherapeutic agent, essentially in the treatment of acute myeloid leukemia. Albino male mice (Mus musculus) are used in this study to determine in vivo toxicity of the drug on spermatogenesis and sperm abnormality. Mice are divided into two groups; the experimental group received a dose of $0.33 \mathrm{mg} / \mathrm{kg} / \mathrm{day}$ Ara-C for seven days, while the control group received normal saline for 7 days. Results indicated a significant increase in head abnormalities percentage $(p \leq 0.05)$ in comparison to control group. Testosterone hormone concentration was significantly decreased $(1.14 \pm 0.12) \mathrm{ng} / \mathrm{ml}$ in treatment group in comparison with control group $(2.41 \pm$ $0.22) \mathrm{ng} / \mathrm{ml}$. Histopathological changes revealed detectable spermatogenesis degeneration. Treatment caused spermatocytes disruption, presence of necrotic cells and appearance of spermiophages with slought cells in several seminiferous tubules. Leydig cells morphology are mostly intact; however, interstitial area appeared hypercellular. It is concluded that Ara-c exposure highly destructive to seminiferous tubule epithelium, which may lead in depressed mice fertility.
\end{abstract}

Key words: Cytarabine, Hitopathological, Testosterone hormone, Sperm heads abnormality.

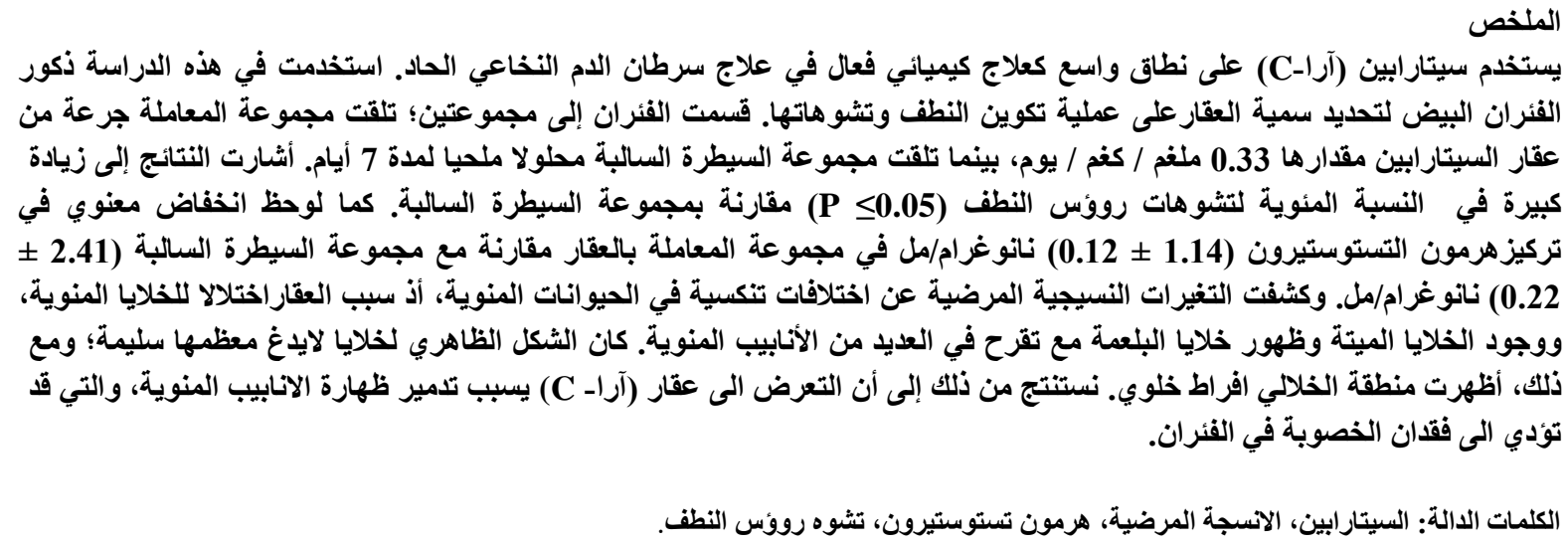

\section{Introduction}

Chemotherapy is a successful treatment approaches in many malignances; however, many problems are still associated with this treatment as it uses a variation of highly toxic agents. The high toxicity and low specificity are probably the problem with this type of treatment [1]. Chemotherapeutic agents have devastating side effects; patients undergo chemotherapy commonly die of pneumonia, common infections or other cancer [2]. The most active drugs are the anthracyclines and the taxanes, followed by alkalating agents, antimetabolites, and vinca alkaloids. They produce objective response rates of 20-80\% [3,4]. However, the rare complete responses are short lived, and progression of disease is almost inevitable [5].

Cytarabine, known as Ara-C, is a chemotherapy agent (antimetabolite) used mostly in the treatment of cancers of white blood cells such as cute Myeloid Leukemia (AML) and non-Hodgkin lymphoma. It kills cancer cells by inhibition of DNA polymerase via competition with deoxycytidine triphosphate, resulting in the inhibition of DNA synthesis. Cytarabine is called cytosine arabinose because it combines a cytosine base with an 
arabinose sugar. Cytosine normally combines with a different sugar, deoxyribose, to form deoxycytidine, a component of DNA. Cytosine arabinoside is similar enough to human cytosine deoxyribose (deoxycytidine) to be incorporated into human DNA, but different enough that kills the cell. This mechanism is used to kill cancer cells [6].

Testicular injury with Leydig cells damage associated with chemotherapy is one of the most common cytotoxicity consequences of treatment in men [7,8]. Although significant research determinations have reduced the cytotoxic effects of many cancer drugs, however, toxicity remains a problem that needs additional improvement. The purpose of this study is to illustrate the effect of cytarabine drug on fertility of albino male mice, the histopathological changes are discussed.

\section{Materials and Methods}

\section{Laboratory Animals}

The study is carried out on Albino male mice (Mus musculus) obtained from Pharmaceutical Control Department (Ministry of Health and Envionment). Twelve mice weighing 23-27g, of 8-9 week age were housed in conventional conditions at animal house laboratory in Ibn Al-Haitham College and fed on a standard pellet and libitium water is added.

\section{Experimental Design}

Twelve male mice are divided into two groups ( $n=6$ each), control group received normal saline and experimental group received subcutaneous Cytarabine (general gift from Baghdad Teaching Hospital) at a final concentration of $0.33 \mathrm{mg} / \mathrm{kg}$ cytarabine from stock of $20 \mathrm{mg} / \mathrm{ml}$ Ara-C for 7 days.

\section{Sperm-Head Abnormality Assay}

Sperm Head Abnormality (SHA) is detected as described by [9], with some modification. After animal scarification by cervical dislocation and dissected, caput and cauda epididymis removed and placed in a Petridish containing $1 \mathrm{ml}$ of physiological normal saline, then minced and teased carefully to release the spermatozoa. After gentle pipetting a drop of $1 \%$ Eosin solution (10:1) is added to the suspension (2-3) drop on clean slide and air dried for $30 \mathrm{~min}$. The percentage of head abnormality is detected under light microscopy using 100X objective.

\section{Tissue Preparation for Histology Preparation}

The left testis and epididymis (caput and cauda) of each mouse is prepared for histopathological study as described by [10]. Samples were fixed in $10 \%$ formalin for $24 \mathrm{~h}$, followed by dehydration with a gradual series of alcohol (30-100\%) for (5)min each. Then the samples cleared in two changes of xylene before embedded in paraffin wax for sectioning. Cross sections of (5) $\mu \mathrm{m}$ thickness are prepared and stained with hematoxylin (Harison) and eosin according to standard method. Histopathlogical changes are performed under light microscope as compared to control group.

\section{Testosterone Serum Level}

Serum level of testosterone hormone is estimated using Mini VIDS (Biomerieux, France) according to manufacturer's standard protocol. All samples are analyzed in triplicate.

\section{Statistical Analysis}

The statistical analysis is performed using Minitab 16 (Minitab Ltd, Coventry, UK). Differences among groups are determined by Student t-test. Data is expressed as mean and standard error and differences were considered significant at $(\mathrm{p} \leq 0.05)$.

\section{Results and Discussion}

\section{Sperm-Head Abnormality (SHA)}

Percentage of sperm head abnormalities is considered one of the important parameter in the evaluation of sperm function. Results showed a significant increases in sperm head abnormalities $(\mathrm{P} \leq 0.05)$ in the experimental group, where the percentage is $6.2 \pm 0.46 \%$ compared with the control group $3.533 \pm 0.24 \%$, Figure $(1,2)$. 


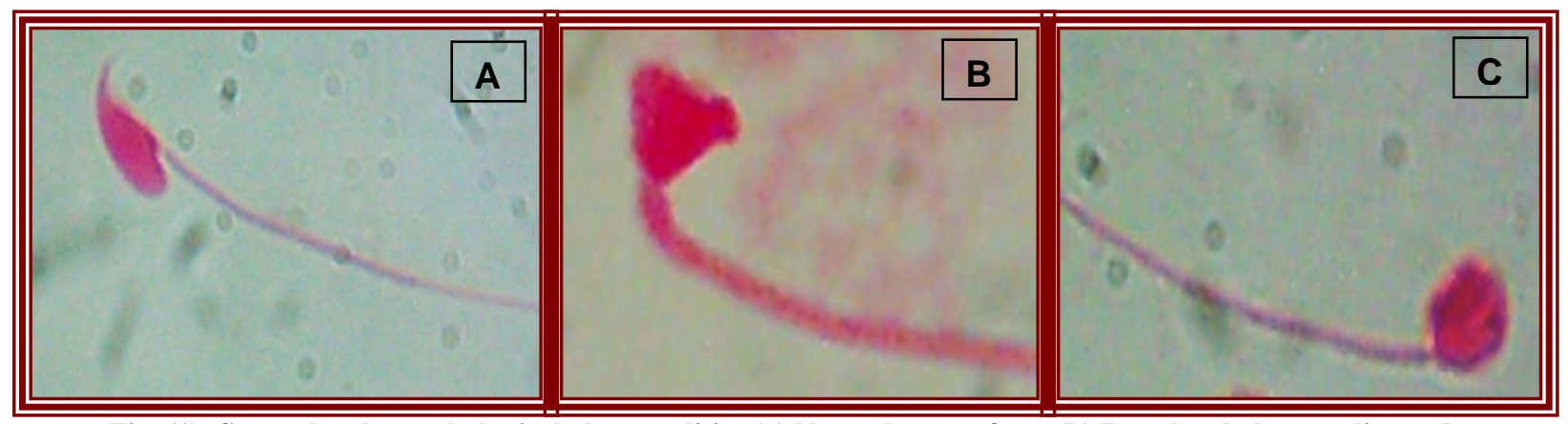

Fig. (1): Sperm head morphological abnormalities (a) Normal sperm form (b) Rose head abnormality and (c) Round sperm head abnormality (hummer head) 100X.

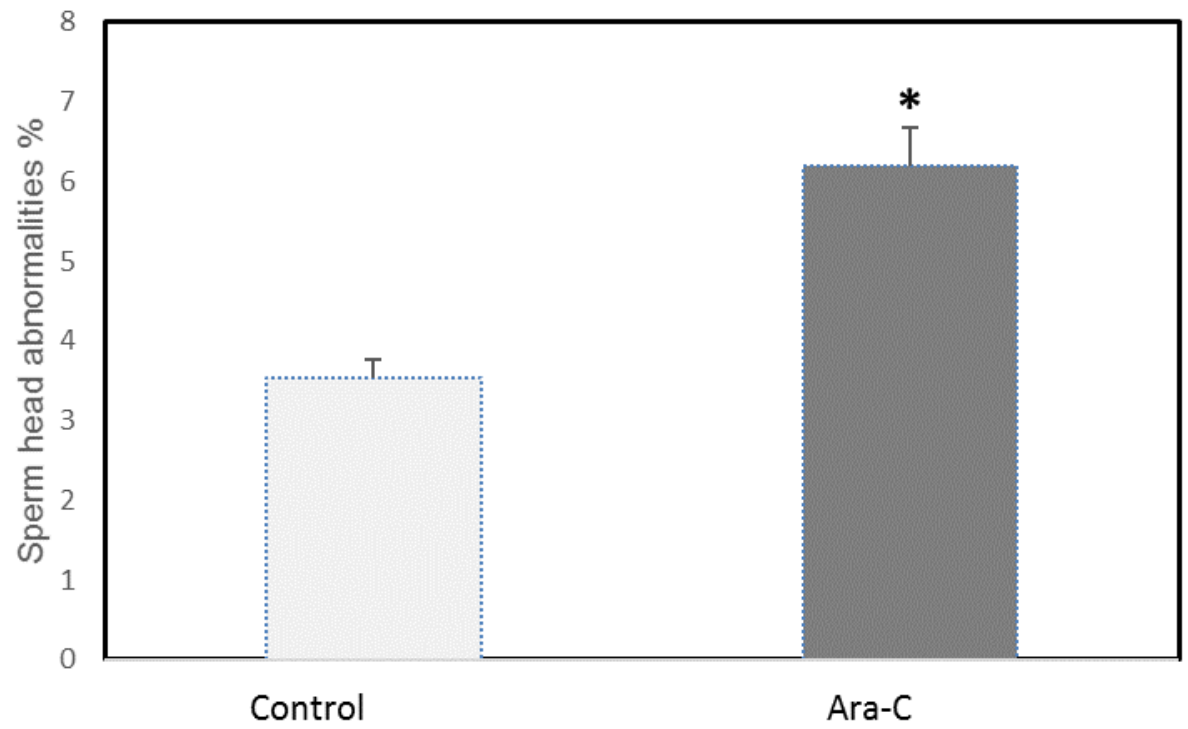

Fig. (2): Percentage of sperm head abnormality in male mouse treated with $0.33 \mathrm{mg} / \mathrm{kg}$ cytarabine $v s$. control. Data are means \pm standard error from triplicate samples. $* \mathbf{p} \leq \mathbf{0 . 0 5}$ Significantly different relative to control.

\section{Histopathological Changes}

\section{Testes}

The results detected several histopathological changes in the treated group in comparison with control group. Where seminiferous epithelium appeared with normal spermatogenesis Figure (3). Evidence of spermatogenesis disruption, germinal cells exfoliation in some tubules and coming loose of different stages of germ cells into the lumina Figure (4). Seminiferous tubules showed atrophy and spermatocytes lining the seminiferous epithelium appeared to be depleted, with the presence of spermatogonia and some primary spermatocytes only and enlargement of seminiferous tubules lumina and increase of interstitial spaces between the seminiferous tubules Figure (5). Presence of some eosinophilic spermiophages cells in some tubules and large vacuole in spermatocytes cytoplasm, some seminiferous tubules showed detachment of germ cells and hypoplasia and necrotic spermatocytes mainly in primary and secondary spermatocytes cells Figure (6). Some of Leydig cells showed nuclear distortion, blood vessels of the interstitial tissue appeared larger and congested. 

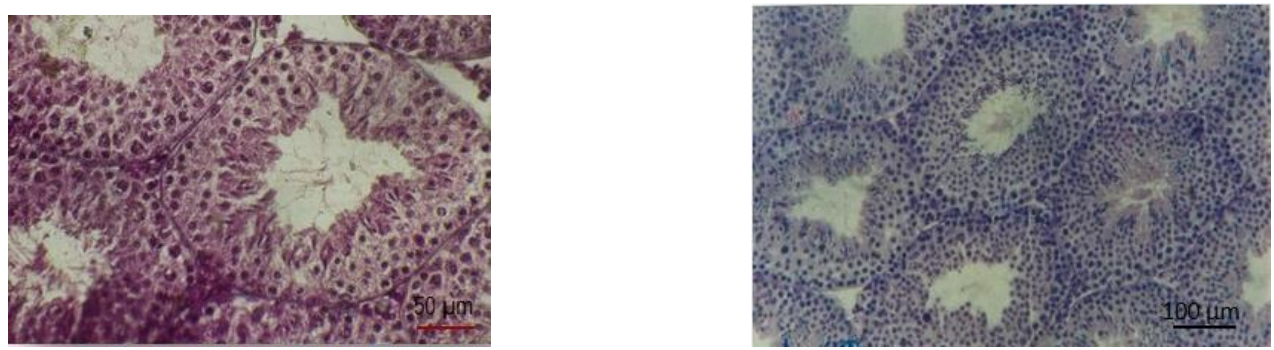

Fig. (3): Section from testis of control mice showing intact seminiferous tubules (bars 50 and $100 \mu \mathrm{m}$ ).

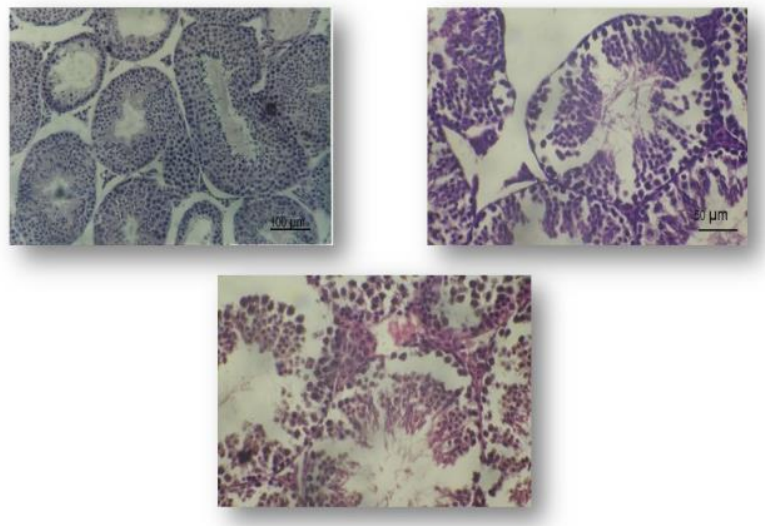

Fig. (4): Section from testis of Are-C treated mice showing disruption and exfoliation in some tubules (bars 50 and $100 \mu \mathrm{m}$ ).
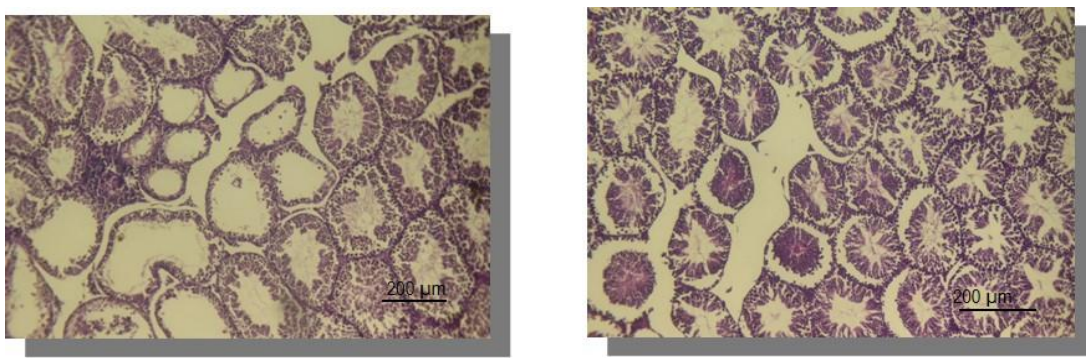

Fig. (5): Section from testis of Are-C treated mice showing atrophy and Increase of interstitial spaces between the seminiferous tubules (bar $200 \mu \mathrm{m}$ ).
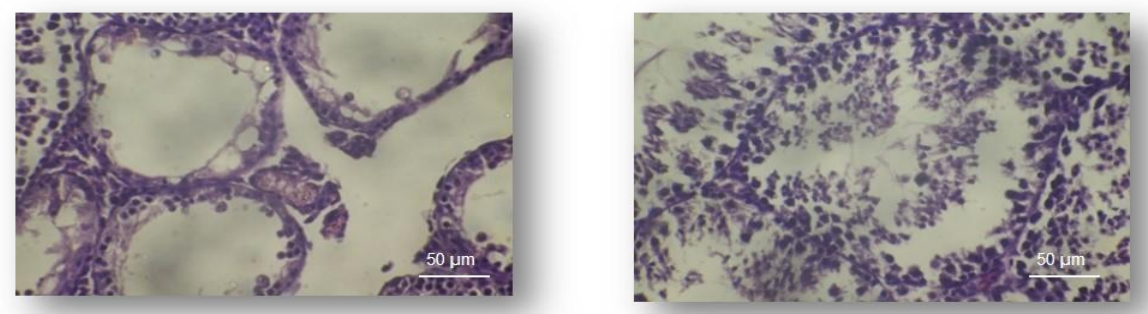

Fig. (6): Section from testis of Are-C treated mice showing some large vacuole in spermatocytes cytoplasm, detachment of germ cells, hypoplasia and necrotic spermatocytes mainly in primary and secondary spermatocytes cells (bar $50 \mu \mathrm{m})$. 


\section{Epididymis}

Epididymis epithelium of control groups showed normal ciliated epithelial cells (columnar cells in the head and cuboidal cells in the tail) based on basement membrane and surrounded by a layer of smooth muscles with connective tissue Figure (7). Epididymis epithelium often red groups showed detachment of epithelial cells from basement membrane and decreased sperms numbers in the luminal tubules with occurs of vacuoles between epithelial cells and some necrotic cells. Increases of interstitial spaces between the tubules Figure (8).
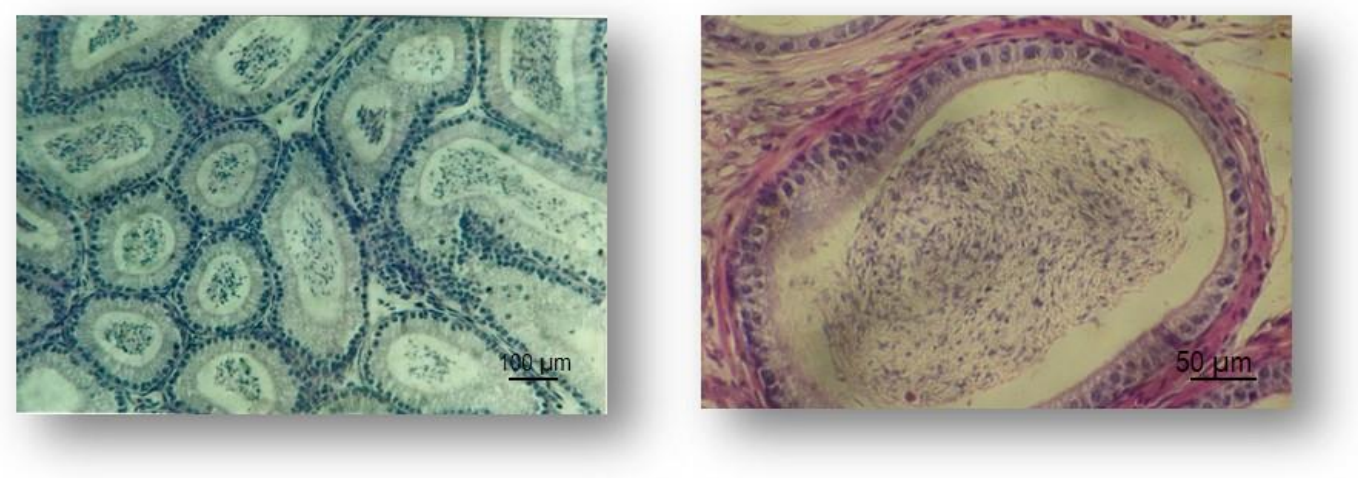

Fig. (7): Section from epididymisof control mice A- head with the columnar epithelial cells, B- tail with the cuboidal epithelial cells (bars 50 and $100 \mu \mathrm{m})$.
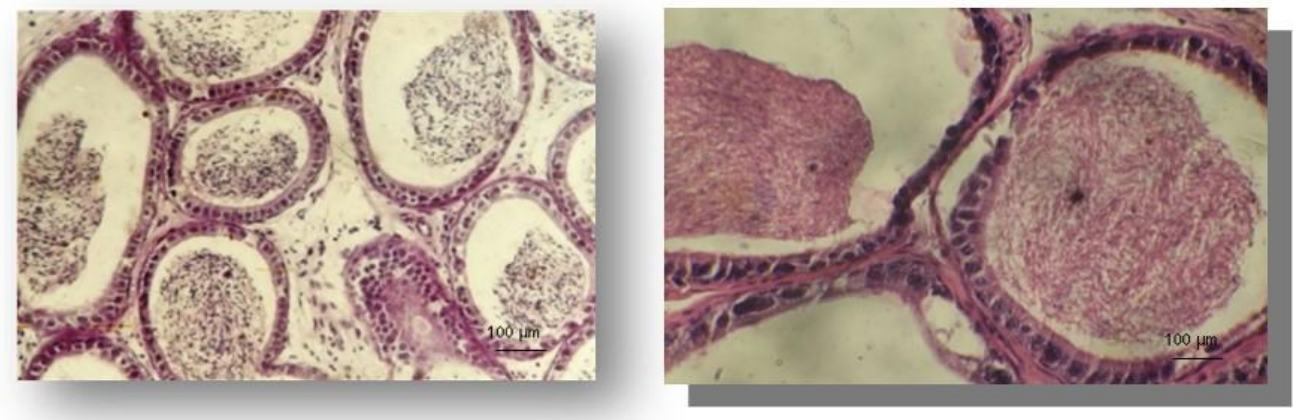

Fig. (8): Section from epididymis of Are-C treated mice showing some large vacuole in the epithelium, detachment of epithelial cells and necrotic cells (bars 50 and $100 \mu \mathrm{m}$ ).

\section{Level of Testosterone}

The mean value of serum hormone level is significantly decreased $(\mathrm{P} \leq 0.05)$ in mice injected with Ara-C compared with mice of control group. The level of Testosteron in the Ara-C treated group and in the control group, respectively showed in Figure (9). 


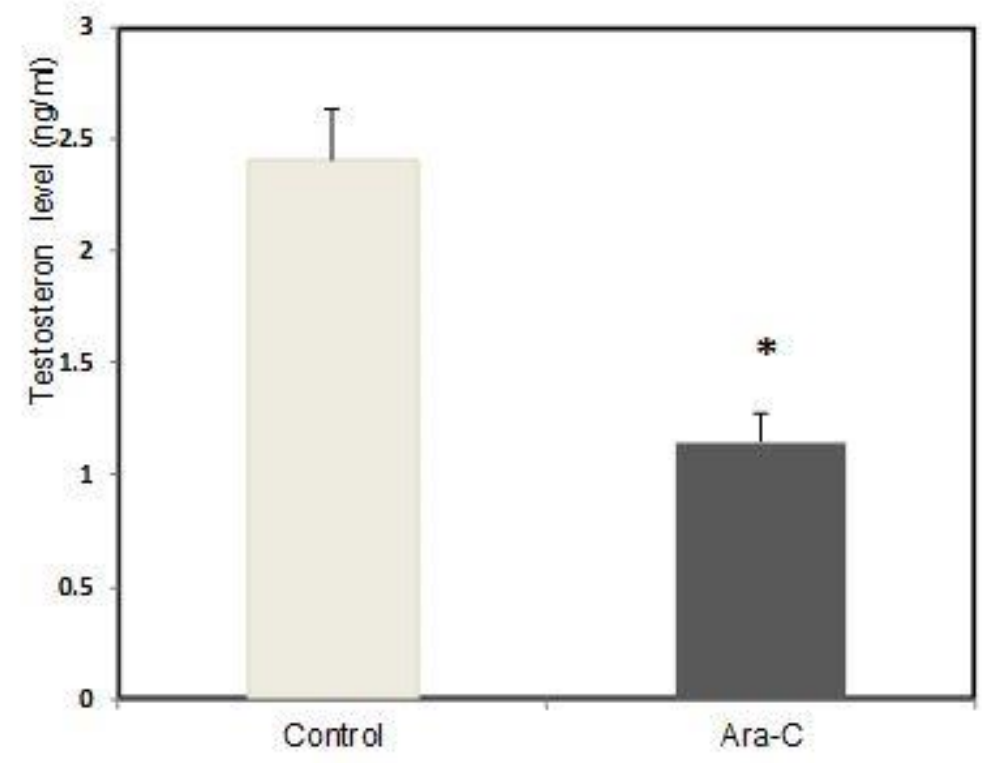

Fig. (9): Serum testosterone level (ng/ml) in male mice treated with $0.33 \mathrm{mg} / \mathrm{kg}$ cytarabine compared with control. Data are means \pm stander error from triplicate samples.

* Significantly different relative to control.

A number of chemicals including various environmental toxicants and even clinically useful drugs can cause cellular damages in different organs of the body through metabolic activation to highly reactive substances such as free radicals [11]. This study investigates Cytarabine induced toxicity in testis mice; study results have been shown that Cytaribine are capable of affecting seminiferous epithelium and altering spermatogenesis process. The results have been indicated that Cytaribine-induced significant increase in the head abnormality associated with severe histopathological changes. The presence of slaughter germinal cells and their occurrence in the epididymis and seminiferous tubule luminal are potential due to the loss of contact as consequences of disruption of cellular junctions between cells. At light microscopy level spermatocyte I and II detention and unformed spermatid possibly contributed to the low spermatic density observed in both seminiferous and epididymis tubules. In contrast, spermatogonia are not affected by the treatment by which some seminiferous tubules contained spermatogonia only. Studies have been reported that spermatogonia seem to be the most resistant spermatogenic cells to toxicity, however, chronic exposure to chemotherapeutic drug [12].

The drug is phosphorylated to nucleotide form, 1- $\beta$-D-arabinofuranosyluracil (Ara-U) by the pymidine nucleoside deaminase (cytidineaminohydrolase), which damages DNA during the cell cycle [13], and specifically G1-phase to S-phase and it has been suggested that Cytarabine acts through the inhibition of DNA and RNA polymerase and nucleotide reductase enzymes which are needed for DNA synthesis. Metabolically, Cytarabine is converted intracellulary to nucleoside triphosphate, which is an inhibitor of DNA polymerase and also incorporated into DNA, where it terminates the strand elongation [14]. Two intracellular enzymes; cytidine deaminase and deoxycytidylate deaminase carry out this activation. The activity of Cytarabine depends on the intracellular phosphorylation by the enzyme cytoplasmic deoxycytidine kinase, which affects the formation of Cytarabine nucleoside triphosphate [15,16]. Moreover, most chemotherapies including Cytarabine are mutagens that have the potential to cause chromosomal aberrations and other structural changes in the DNA material $[17,18]$.

The successful and complete male germ cell development is depended on the balanced endocrine of hypothalamus, pituitary and the testis. Gonadotropin releasing hormone secreted by the hypothalamus elicits the release of gonadotropins hormones from the pituitary gland. FSH binds with receptors in the Sertoli cells and stimulates spermatogenesis. LH stimulates the production of testosterone in Leydig cells, which in turn 
may act on Sertoli cells and stimulates spermatogenesis [19]. Decreased the level of testosterone in this study by Cytarabine is probably impaired due to excessive oxidative stress and the degeneration of Leydig cells; metabolites of the testosterone in return depress FSH and LH secretion.

It is concluded from this study, that the cytotoxic effects of Cytarabine on male reproductive system suggested that using Cytarabine for seven days causing reduction in the fertility. However, further studies are required to identify the specific underling mechanisms and how to minimize the destructive ability of Cytarabine to the male reproductive system.

\section{References}

1. Larsen, H. R. (1996). Cancer: causes, prevention and treatment. Int. J. of Alternative and Complementary Medicine, 14: 9-11.

2. Walters, R. (1993). Options: The Alternative Cancer Therapy. Garden City Park, NY: 9-13.

3. Bernard-Marty, C., Cardoso, F., and Picart, M. J. (2004). Facts and controversies in systemic treatment of metastatic breast cancer. The Oncologist, 9: 617-632.

4. Ellis, M. J., Hayes, D. F., and Lippman, M. E. (2000). Treatment of metastatic breast cancer. Philadelphia, Lippincott Williams and Wilkins: 749.

5. Cardoso, F., Dileo, A. and Lohrisch, C. (2002). Second and subsequent lines of chemotherapy for metastatic breast cancer: What did we learn in the last two decades? Ann. Oncol, 13: 197-207.

6. Konda, N., Prashanth, P., Arvind, G., and Shah, S. (2013). Pharmaceutical development and compatibility studie soncytarabine injection. Asian J. Pharm. Clin. Res., 6, 3: 142-145.

7. Holmes, S. J., Whitehouse, R. W., and Clark, S. T. (1994). Reduced bone mineral density in men following chemotherapy for Hodgkin's disease. Br. J. Cancer, 70, 371-375.

8. Pryzant, R. M., Meistrich, M. L., and Wilson, G. (1993). Long term reduction in sperm count after chemotherapy with and without radiation therapy for non-Hodgkin's lymphomas. J. Clin. Oncol. 11: 239-247.

9. Wyrobek, A. J. and Bruce, W. R. (1975). Chemical induction of sperm Abnormalities in mice. Proc. Natl. Acad. Sci., 72: 4425-4429.

10. Alwachi, S. N. and Husain, D. K. (2014). Research article Tamsulosin hydrochloride (flomax) effects on fertility of albino male mice. International Journal of Recent Scientific Research. 5, 2: 326-331.

11. Lemike, T. L., Williams, D. H., and Foye, W. O. (2002). Principles of medicinal chemistry. Hagerstwon, 963 975.

12. Howell, S. J. and Shalet, S. M. (2001). Testicular function following chemotherapy. European society of human reproduction and embryology. 7,4:363-369.

13. Dedrick, R. L., Forrester, D. D., Cannon, J. N., El-Dareer, S. M., and Mellett, L. B. (1973). Pharmacokinetics of 1-b-D-Arabinofuranosylcytosine (Ara-C) deamination in several species. Biochemical Pharmacology, 22, 19: $2435-2417$.

14. Yin, B. (2006). Nf1 gene inactivation in acute myeloid leukemia cells confercytarabine resistance through MAPK and mTOR pathways. Leukemia, 20: 151-154.

15. Li, Z., Gao, J., Zhao, W., and Li, Z. (2015). Dissolution characteristics of anti-cancer drug Cytarabine. J. Chem. Pharm. Res., 7, 1: 68-72.

16. Lombardo, A. and Nichols, E. (2009). Toxicity and anti- tumor effects of cytarabine and doxorubicin on acute myeloid leukemia. A major qualifying project report submitted to the Faculty of the Worcester polytechnic Institute, Biology and Biotechnology and Biochemistry.

17. Wang, W.S., Tzeng, C. H., and Chiou, T. J. (1997). High-dose cytarabine and mitoxantrone as salvage therapy for refractory non-Hodgkin's lymphoma. Jpn. J. Clin. Oncol. 27, 3: 154-57.

18. Tallman, M. S. (2005). Drug therapy for acute myeloid leukemia. Blood, 106: 1154-1163.

19. Al-Hadidyai, A.A.A. (2003). Estimation of testosterone and some biochemical parameters in infertile women's serum. Thesis supplement to Microbiology Department, Medicinal College, Mosul. 